\title{
Além do Centro-Sul: por uma história da população colonial nos extremos dos domínios portugueses na América (projeto integrado)
}

\author{
Sérgio Odilon Nadalin* \\ Dario Scott ${ }^{\star *}$
}

0 projeto concernente a esta nota de pesquisa associa nos seus objetivos os interesses de vários pesquisadores que constituem o Grupo de Pesquisa Demografia \& História, vinculados a diversos centros de pesquisa e programas de pós-graduação. Em síntese, a nossa intenção mais ampla é estabelecer as bases para a discussão dos regimes demográficos da população brasileira no passado. Com essa finalidade, estamos nos concentrando em "salvar" a memória populacional contida nas atas paroquiais de algumas freguesias selecionadas.

Palavras-chave: Memória demográfica. Regimes demográficos. Arquivos paroquiais. Fontes paroquiais. Império colonial português.

\footnotetext{
*Universidade Federal do Paraná (UFPR), Curitiba-PR, Brasil (sergion@terra.com.br).

** Universidade Estadual de Campinas (Unicamp), Campinas-SP, Brasil (dariostt@gmail.com).
} 


\section{Introdução}

0 presente texto aborda o desenvolvimento, desde 2008, de um projeto integrado sob a supervisão do Grupo de Pesquisa Demografia \& História, ancorado na Universidade Federal do Paraná. Desde então, atividades de pesquisa foram realizadas em São Leopoldo, Belém, Campinas, São Paulo, Marília e Natal, lideradas por integrantes do grupo ${ }^{1}$ e com apoio financeiro do CNPq. Trata-se, portanto, de um projeto de abrangência nacional e de longo fôlego, que padronizou procedimentos metodológicos para a coleta e o tratamento das fontes documentais, possibilitando análises comparadas no tempo e no espaço e expandindo os estudos de história demográfica. Nesse sentido, os membros do grupo almejam, por meio da exploração sumária e amostral da documentação selecionada, demonstrar a viabilidade do projeto e dar início a uma discussão a respeito dos regimes demográficos diferenciados do passado brasileiro (NADALIN, 2003, 2014).

Visando tais objetivos, o grupo discutiu o conteúdo de um banco de dados construído a partir das informações de atas paroquiais de batismos, casamentos e óbitos. Essas informações fundamentaram o núcleo do software, denominado NACAOB, ${ }^{2}$ sob a supervisão técnica de Dario Scott.

\section{0 problema}

0 interesse pela história da população esteve presente desde os primórdios da historiografia brasileira, a partir dos esforços iniciais do Instituto Histórico e Geográfico do Brasil (IHGB) para compreender o processo de formação do "povo brasileiro".

Tais estudos formaram as bases do conhecimento a respeito da população brasileira que, por força mimética, repetiram-se, com pequenas inovações, em trabalhos acadêmicos e manuais escolares do século XIX e primeiras décadas do século XX, até a publicação da revolucionária obra Casa grande \& senzala, de Gilberto Freyre.

À medida que adentrava o século XX, os investigadores acrescentaram tópicos específicos à contribuição dos contingentes europeus. Porém, as mudanças da década de 1960 para a de 1970 incluíram nova revolução nesse campo de interesse. Pesquisadores de renomadas instituições universitárias trouxeram para o Brasil o resultado de seus diálogos com historiadores e demógrafos europeus, particularmente os ligados às instituições francesas e inglesas, introduzindo em determinados centros de pesquisa novas formas de

\footnotetext{
${ }^{1}$ Ana Silvia Volpi Scott e Dario Scott (Unicamp), Antonio Otaviano Vieira Jr. (UFPA), Maísa Faleiros da Cunha (Unicamp), Carlos Bacellar (USP), Paulo Eduardo Teixeira (Unesp) e Luciana Conceição de Lima (UFRN). Uma comunicação a respeito foi realizada em 2009; ver Nadalin et al. (2009).

${ }^{2}$ NAscimento, CAsamento, ÓBitos, NACAOB. Como informa o espelho do grupo de pesquisa, trata-se de "software desenvolvido por Ana Silvia Volpi Scott e Dario Scott para inclusão de registros paroquiais e outras fontes nominativas para possibilitar a reconstituição de famílias a partir da metodologia proposta por Louis Henry. 0 sistema foi desenvolvido em C\# e utiliza um banco de dados SQL. O software roda sob o sistema operacional Windows XP ou superior e é necessária a instalação da biblioteca Microsoft NET Frameword 3.5”. (SCOTT; SCOTT, 2009, p. 171-85).
} 
a historiografia tratar a matéria população. Era época de plena implantação dos programas de pós-graduação, e membros de diversas instituições perfilhavam-se no entusiasmo por adensar o conhecimento historiográfico, utilizando metodologias propostas pela história demográfica que, na Europa, estava em efervescência desde a década de 1950.

Sintetizando, o fato é que o encaminhamento demográfico permitiu conhecer, por vezes com alto grau de refinamento, comportamentos das populações coloniais radicadas notadamente no Sudeste brasileiro, embora focando o período posterior à passagem do século XVIII para o XIX. É fato, também, que, apesar dos progressos evidenciados, ainda pouco ou nada se sabe a respeito das dinâmicas populacionais do período anterior aos oitocentos e/ou vivenciadas nas demais partes do país.

A fim de mapear o problema, foram consideradas algumas variáveis, como a maior ou menor mobilidade da população colonial portuguesa e a migração consequente, movendo junto as estruturas sociais, simultaneamente definindo fronteiras geográficas, demográficas e etno-culturais. ${ }^{3}$ Esses múltiplos processos, interligados, resultaram em estruturas sociais complexas, daí a dificuldade para se ir mais a fundo em qualquer generalização a respeito dos regimes populacionais implantados na Colônia.

Entretanto, uma questão a ser salientada (pois foi apenas referida mais acima) diz respeito à estabilidade da população. Foi sugerido um modelo relacionado à singularidade histórica de uma sociedade "móvel”, que se caracteriza, inclusive, por uma relativa instabilidade familiar e pelo contraponto, também original, de uma população mais estável instalada no litoral e, quase essencialmente, no Nordeste (NADALIN, 2003). Na extremidade, um modelo demográfico urbano, de fraco crescimento vegetativo, e cuja dinâmica baseava-se no ingresso constante de novos contingentes populacionais oriundos da imigração; mais ou menos no seu "interior", regimes demográficos "restritos", fundados quer na escravidão, quer em economias familiares de subsistência mais ou menos estáveis, ou na economia do gado. Regimes demográficos que se sucedem e se superpõem no tempo e no espaço, que opõem, em dicotomias complexas, "estabilidade" e "instabilidade", "aventura" e "trabalho", o "litoral” e o "planalto", “aglomerações urbanas” e a "rarefação sertaneja”, a "floresta” e o “campo”. No plural, esses tempos e espaços foram construídos pela distensão demográfica a partir das regiões litorâneas (e de São Paulo da Piratininga), originando, em alguns momentos, outros sistemas irradiadores.

Há que se considerar, finalmente, as enormes dimensões do Império português e o próprio tamanho do território "brasileiro", demandando distintas estratégias coloniais e o aproveitamento de especialidades regionais, definidas de acordo com os interesses metropolitanos. Da mesma forma, deve-se levar em conta o tempo extremamente largo no qual se insere o tema, desde o século XVI até o XVIII, espraiando-se inclusive até 1850, após a Independência.

\footnotetext{
$\overline{3}$ Essa questão foi desenvolvida em Nadalin (2003, 2009, 2014).
} 


\section{Objetivos}

O objetivo geral do projeto é estabelecer as bases para a discussão dos regimes demográficos da população brasileira no passado. Considerando-se que a proposta apoia-se nos registros paroquiais concernentes, principalmente, ao período colonial nas regiões Norte, Nordeste e extremo sul da América portuguesa, também é nosso objetivo salvar essas fontes de dados e, dessa forma, divulgar e ampliar os estudos populacionais no Brasil, com o software NACAOB e a montagem de equipes que trabalhem com registros paroquiais do Norte até o Sul do passado do Brasil. Abre-se, desse modo, um poderoso flanco de pesquisa, perdendo força as explicações genéricas e fomentando a análise das especificidades locais e de pontos nacionais comuns.

O grupo Demografia \& História constituiu-se tendo em vista dois grandes objetivos, que marcam as linhas de pesquisa inscritas no CNPq. 0 projeto concernente, portanto, alinhava-se, a partir do tema de uma história da população brasileira, na necessidade de compreender a complexidade da dinâmica demográfica a partir dos denominados "regimes demográficos" e, motivação não menos importante, no necessário "resgate" das suas fontes: neste projeto apontamos, preferencialmente, para a documentação constituída pelas atas das paróquias coloniais. De fato, desde que os mórmons realizaram a ampla tarefa de microfilmagem dessas fontes, cobrindo parcialmente paróquias cuja documentação sobreviveu à destruição das fontes históricas brasileiras, muito dos originais copiados e que constam do acervo de Salt Lake City já desapareceram, destruídos pelo tempo e (ou) por outros motivos.

Em consequência, o grupo espera poder demonstrar as possibilidades de utilização da documentação agora digitalizada, utilizando, para tanto, o NACAOB 14.02. Esta décima quarta versão do NACAOB, desenvolvido por Dario Scott, ensejará o arrolamento e tratamento das informações - num primeiro momento, a "exploração sumária dos dados" (FLEURY; HENRY, 1965, p. 31). Em consequência, as comparações regionais, devidamente qualificadas em função dos regimes demográficos que vigoraram no passado, permitirão verificar a justeza e o mérito das ações empreendidas até o momento.

Mais adiante, a partir da criação de redes de pesquisadores centrados em várias regiões do país e construídas a partir das iniciativas do grupo de pesquisa, espera-se gradativamente completar a indexação da documentação: nossa meta final, num longo prazo, seria a de construir um banco de dados nacional, a ser acessado a partir de site especialmente criado. A rede de pesquisadores envolvida deverá contribuir, finalmente, para as análises sumárias da documentação, tendo em vista o quadro teórico-metodológico construído a partir do conceito dos regimes demográficos.

Finalmente, é necessário salientar que a exploração sucinta das séries comparáveis de informações propiciadas por uma amostra de paróquias do Norte, Nordeste e extremo sul deverá não só autorizar a construção de interfaces institucionais voltadas aos estudos de história da população brasileira, como também avançar o conhecimento relativo aos regimes demográficos no passado brasileiro. 


\section{Resultados preliminares}

A intenção inicial do grupo de pesquisa era focar as investigações em regiões mal cobertas pela historiografia demográfica e social. Explica-se, assim, o título do projeto, pois estávamos motivados pela necessidade de fomentar pesquisas nessas regiões "além do Centro-Sul" e, o que também é caro ao grupo, salvar a documentação paroquial, que está, em muitos locais, em estado precário. Todavia, dado o avanço anterior do trabalho de indexação de dados da Paróquia Madre de Deus, em Porto Alegre, decidimos investir também nesta Freguesia, para termos um dado comparativo com uma localidade cujos registros paroquiais estão muito bem conservados. ${ }^{4}$

Incluindo alguns resultados "tentativos", foram arrolados até o momento 85.356 batismos, 11.242 casamentos e 51.246 óbitos no banco de dados; destes, 67.693 batismos, 8.091 casamentos e 46.618 óbitos fazem parte do projeto em andamento, conforme mostra a Tabela 1. Isso ainda é pouco diante do que o grupo ambiciona: trata-se de um trabalho que exige meticulosidade, cuidado e paciência. Tendo em vista os principais objetivos do projeto, não ousamos fixar metas, não só em função dos problemas de produtividade, mas também porque dependemos muito dos aportes do CNPq que, sabemos, podem terminar.

TABELA 1

Indexação de dados realizada até 31 de dezembro de 2016 da população livre e escrava, segundo paróquias/freguesias - séculos XVIII-XX

\begin{tabular}{|c|c|c|c|c|}
\hline Paróquias/Freguesias & Categorias & Período & Total indexado & Observações \\
\hline \multirow{3}{*}{$\begin{array}{l}\text { Madre de Deus, Porto Alegre, } \\
\text { RS (1) }\end{array}$} & Batismos & $1772-1854$ & 25.233 & \\
\hline & Casamentos & $1772-1849$ & 4.189 & \\
\hline & Óbitos & $1772-1872$ & 32.012 & \\
\hline \multirow[t]{3}{*}{ N.S. da Conceição do Viamão, RS (2) } & Batismos & - & - & \\
\hline & Casamentos & - & - & \\
\hline & Óbitos & 1745-1799 & 1.761 & \\
\hline \multirow[t]{3}{*}{ Sé, Belém do Pará (3) } & Batismos & $1775-1889$ & 22.686 & \\
\hline & Casamentos & $1830-1854$ & 335 & \\
\hline & Óbitos & - & - & \\
\hline \multirow[t]{3}{*}{ N.S. Nazaré, Belém do Pará (4) } & Batismos & 1870-1889 & 5.861 & \\
\hline & Casamentos & - & - & \\
\hline & Óbitos & - & - & \\
\hline \multirow[t]{3}{*}{ Quixeramobim, Ceará (5) } & Batismos & $1755-1834$ & 6.797 & Lacunas: 1760-1799 \\
\hline & Casamentos & - & - & \\
\hline & Óbitos & - & - & \\
\hline \multirow{3}{*}{$\begin{array}{l}\text { N.S. da Apresentação, Rio Grande } \\
\text { do Norte (6) }\end{array}$} & Batismos & $1680-1874$ & 3.540 & Lacunas: 1715-1754 \\
\hline & Casamentos & $1725-1914$ & 2.011 & Lacunas: 1790-1889 \\
\hline & Óbitos & $1745-1954$ & 9.594 & Algumas lacunas \\
\hline
\end{tabular}

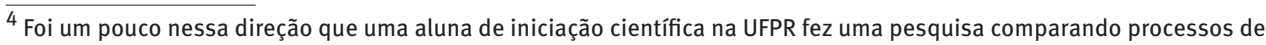
nominação em Belém do Pará e em Porto Alegre (PAROL, 2014).
} 
(continuação)

\begin{tabular}{llccc}
\hline Paróquias/Freguesias & Categorias & Período & Total indexado & Observações \\
\hline N.S. Prazeres de Goianinha, RN (7) & Batismos & $1845-1889$ & 2.263 & \\
& Casamentos & $1825-1889$ & 1.506 & \\
& Óbitos & $1815-1859$ & 3.251 & Algumas lacunas \\
\hline Santiago do Iguape, Bahia (8) & Batismos & $1700-1809$ & 4.622 & Lacunas: 1755-1794 \\
& Casamentos & - & - & \\
& Óbitos & - & - & \\
\hline São Pedro Mártir, Olinda, & Batismos & $1820-1839$ & 1.313 & \\
Pernambuco (9) & Casamentos & $1815-1824$ & 50 & \\
& Óbitos & - & - & \\
\hline
\end{tabular}

Fonte: Base de dados do NACAOB em 31/12/2016.

(1) Indexação adiantada, a cargo das equipes monitoradas pela Dra. Ana Silvia Volpi Scott da Unisinos (2008 a 2015) e Unicamp (a partir de maio de 2015).

(2) Indexação apenas iniciada, a cargo de equipe monitorada pela Dra. Ana Silvia Volpi Scott.

(3) Indexação terminada, a cargo da equipe monitorada pelo Dr. Antonio Otaviano Vieira Jr., da UFPA. Os livros de óbitos e a

maioria dos livros de casamentos encontram-se extraviados.

(4) Indexação por ora interrompida.

(5) Indexação interrompida, em função do mau estado dos livros.

(6) Indexação adiantada, a cargo da equipe monitorada pela Dra. Luciana Conceição de Lima, da UFRN.

(7) Indexação adiantada, a cargo da equipe monitorada pela Dra. Luciana Conceição de Lima, da UFRN

(8) Indexação iniciada, a cargo da equipe monitorada pelo Dr. Carlos Bacellar, da USP.

(9) Indexação apenas iniciada, a cargo da equipe monitorada pelo Dr. Paulo Eduardo Teixeira, da Unesp.

Por outro lado, dezenas de estudantes têm passado por nossas mãos, aprendendo paleografia, conhecendo melhor as virtualidades dos registros paroquiais e utilizando os dados para elaborarem seus trabalhos de final de curso, dissertações de mestrado e teses de doutorado.

Com exceção dos dados indexados para o Rio Grande do Sul, que têm possibilitado a elaboração de trabalhos de final de curso, dissertações de mestrado e teses de doutorado, é preciso ainda investir muito, principalmente nas frentes que estão se abrindo para a Bahia e Pernambuco. Estamos ainda um pouco distantes dos resultados já obtidos por Scott e Scott (2009) e pelos alunos do Programa de Pós-graduação em História da Unisinos que estavam integrados à equipe do projeto até 2015, mas há que persistir.

\section{Potencialidades do NACAOB ${ }^{5}$}

Foram as Constituições Primeiras do Arcebispado da Bahia (1707) que regulamentaram a vida religiosa na colônia lusa na América. ${ }^{6}$ Apesar disso, encontramos muita variação na qualidade da informação dos documentos, que dependia do zelo e da eficiência dos párocos, responsáveis por elaborar as atas.

A vantagem de utilizar o NACAOB está na padronização dos dados coletados, sem perder nenhuma informação da fonte original. Isso possibilita aos pesquisadores que estudam diferentes regiões efetuar comparações diretas dos seus resultados. 0 software possui

\footnotetext{
${ }^{5}$ Disponivel em: 〈http://www.nacaob.com.br〉

${ }^{6}$ Ver Monteiro (2007).
} 
tabelas que são comuns a todos os pesquisadores, como nomes, ${ }^{7}$ ocupações, residência, títulos e patentes, naturalidade, cor, assinatura, condição jurídica, estado matrimonial, etc., mantendo assim uma estandardização na coleta da informação.

Como uma das propostas do projeto é o resgate dessa documentação, o NACAOB permite que se reproduza toda a informação dos assentos, possibilitando, assim, verificar as modificações ocorridas em cada variável registrada ao longo do tempo para cada indivíduo, quer dizer, variações de nome, atributos, condição matrimonial, etc., em cada assento em que ele participou, e qual o papel desse indivíduo no evento.

Com relação aos proprietários e escravos, o sistema também possibilita recompor as escravarias, pelo menos de todos os que nasceram, casaram ou morreram e foram registrados na freguesia estudada.

Toda a potencialidade do NACAOB em relação ao cruzamento com outras fontes pode ser vista em Ana Scott $(1999,2012)$. A autora explorou o cruzamento nominativo dos assentos paroquiais, entre outras fontes, com Róis de Confessados e Testamentos.

\section{Referências}

FLEURY, M.; HENRY, L. Nouveau manuel de dépouilleiment et d'exploitation de l'état civil ancién. Paris: INED, 1965.

GOLDSCHMIDT, E. Prostituição (verbete). In: SILVA, M. B. N. da (Org.). Dicionário da história da colonização portuguesa no Brasil. Lisboa: Verbo, 1994. p. 669-72.

HOLANDA, S. B. de. Raízes do Brasil. 4. ed. Brasília: Edit. da UNP, 1963.

KREAGER, P. Demographic regimes as cultural systems. In: COLEMAN, D.; SCHOFIELD, R. (Ed.). The state of population theory. Nova York: Basil Blackwell Ltd, 1986.

MARCílIO, M. L. Sistemas demográficos no Brasil do século XIX. In: MARCílIO, M. L. (Org.). População \& sociedade: evolução das sociedades pré-industriais. Petrópolis: Vozes, 1984. p. 193-207.

MARTIUS, C. F. Como se deve escrever a história do Brasil. Revista do IHGB, v. 1, n. 10, p. 149-157, 1841.

MONTEIRO, S. da. Constituições Primeiras do Arcebispado da Bahia/feitas e ordenadas pelo ilustríssimo, e reverendíssimo senhor d. Sebastião Monteiro da Vide, bispo do dito arcebispado, e do Conselho de Sua Majestade: propostas, e aceitas em o Sínodo Diocesano, que o dito senhor celebrou em 12 de junho do ano de 1707. Brasília: Senado Federal, 2007.

NADALIN, S. O. A população no passado colonial brasileiro: mobilidade versus estabilidade. Topoi (Revista de História. Programa de Pós-Graduação em História Social da UFRJ), v. 4, n. 7, p. 222-275, jul./dez. 2003.

História e demografia: elementos para um diálogo. Campinas: Associação Brasileira de Estudos Populacionais - Abep, 2004.

\footnotetext{
${ }^{7}$ A tabela de NOMES do NACAOB possui um dicionário em que o pesquisador insere o nome com a grafia original do documento (Joseph, por exemplo) e, se o nome nunca foi inserido, o programa abre uma nova janela para a inserção da grafia atualizada correspondente a esse nome (José). Isso permite que o cruzamento nominativo seja feito de maneira mais eficiente, pela grafia atualizada, impedindo, assim, que grafias diferentes do mesmo nome (Joseph e José) gerem problemas no processo do cruzamento automático.
} 
. Questões referentes aos regimes demográficos no passado colonial brasileiro. In: SCOTT, A. S. et al. Gentes das Ilhas: trajetórias transatlânticas dos Açores ao Rio Grande de São Pedro entre as décadas de 1740 a 1790. São Leopoldo: Oikos, 2014. p. 13-30.

NADALIN, S. O. et al. Más allá del Centro-Sur: por uma historia de la población colonial em los extremos de los domínios portugueses em América (siglos XVII-XIX). In: CELTON, D.; GHIRARDI, M.; CARBONETTI, A. (Org.). Poblaciones históricas: fuentes, métodos y líneas de investigación. 1. ed. Rio de Janeiro: Alap Editor, 2009. p. 137-53.

PAROL, N. Processos comparados de nominação: Belém (PA) e Porto Alegre (RS), séculos XVIII e XIX. Relatório Técnico de Iniciação Científica. Curitiba: Universidade Federal do Paraná, 2014.

REINHARD, M. R. et al. Histoire générale de la population mondiale. Paris: Montchrestien, 1968.

RIBEIRO, J. História do Brasil. 5. ed. Rio de Janeiro: Francisco Alves, 1914.

ROWLAND, R. População, família, sociedade: Portugal, séculos XIX-XX. Oeiras: Celta Editora, 1997. População, desenvolvimento e estrutura social em perspectiva histórica: os regimes demográficos e seus contextos. Revista Estudos Amazônicos, v. 9, n. 1, p. 267-309, 2013.

SCOTT, A. S. V. Famílias, formas de união e reprodução social no noroeste português (século XVIII e XIX). Guimarães: Eden, 1999. (Coleção Monografias NEPS, v. 6).

Famílias, formas de união e reprodução social no noroeste português (século XVIII e XIX). São Leopoldo: Oikos, 2012 (Coleção EHILA, v. 5).

SCOTT, A. S. V.; SCOTT, D. NACAOB: una opción informatizada para historiadores de la familia. In: CELTON, D.; GHIRARDI, M.; CARBONETTI, A. (Org.). Poblaciones históricas: fuentes, métodos y líneas de investigación. 1. ed. Rio de Janeiro: Alap Editor, 2009. p. 171-85.

VILAR, P. Iniciación al vocabulario del analisis histórico. Barcelona: Crítica, 1980.

\section{Sobre os autores}

Sérgio Odilon Nadalin é doutor em História e Geografia das Populações pela École des Hautes Études en Sciences Sociales (EHESS, Paris). Professor sênior do Programa de Pós-Graduação em História da Universidade Federal do Paraná (UFPR) e pesquisador sênior do CNPq.

Dario Scott é doutorando em Demografia pela Universidade Estadual de Campinas (Unicamp) e mestre em Computação Aplicada pela Universidade do Vale do Rio dos Sinos (Unisinos).

\section{Endereço para correspondência}

Sérgio Odilon Nadalin

Rua Bororós, 555, Vila Izabel

80320-260 - Curitiba-PR, Brasil

Dario Scott

Alameda Carlos Barduchi, Lote 12 - Dois Córregos

13278-170 - Valinhos-SP, Brasil 


\begin{abstract}
Beyond Center-South: for a history of colonial population at the extremes of Portuguese domination in America (integrated project)

The project regarding this research note relates in its objectives the interests of several researchers who constitute the "Demography \& History" Research Group, linked to several research centers and postgraduate programs. To sum up, our broader intention is to lay the groundwork for the discussion of the demographic regimes of the Brazilian population in the past. To that end, we are focused on "saving" the population memory contained in parochial records from selected parishes.
\end{abstract}

Keywords: Demographic memory. Demographic regimes. Parochial records. Parish sources. Portuguese colonial empire.

\title{
Resumen
}

Más allá del Centro-Sur: por una historia de la población colonial en los extremos de los dominios portugueses en América (proyecto integrado)

El proyecto de investigación vinculado con esta nota incluye en sus objetivos el interés de muchos investigadores que constituyen el Grupo de Investigación «Demografía e Historia», relacionado con varios centros de investigación y programas de posgrado. En resumen, nuestra intención más amplia es establecer las bases para la discusión de los regímenes demográficos de la población brasileña en el pasado. Con este fin, nos estamos centrando en «salvar» la memoria de la población contenida en los archivos de algunas parroquias seleccionadas.

Palabras clave: Memoria demográfica. Regímenes demográficos. Archivos parroquiales. Fuentes parroquiales. Imperio colonial portugués. 
